\title{
Color of low-fat cheese influences flavor perception and consumer liking
}

\author{
R. Wadhwani and D. J. McMahon ${ }^{1}$ \\ Western Dairy Center, Department of Nutrition, Dietetics, and Food Sciences, Utah State University, Logan 84322-8700
}

\begin{abstract}
The present study examines the effect of color on low-fat cheese flavor perception and consumer acceptability. To understand the flavor preferences of the consumer population participating in the sensory testing, 4 brands of retail full-fat Cheddar cheeses labeled as mild, medium, or sharp were obtained. These cheeses were evaluated by a trained descriptive panel to generate a flavor profile for each cheese and then by consumer sensory panels. Overall and color liking were measured using a 9-point hedonic scale, and flavor, chewiness, level of sharpness measured using a 5-point just-aboutright (JAR) scale (with 1 being not enough, 3 being just about right, and 5 being too much of the attribute). Subsequently, 9 low-fat Cheddar cheeses were manufactured using 3 levels of annatto $(0,7.34$, and $22 \mathrm{~g} / 100 \mathrm{~kg})$ and 3 levels of titanium dioxide $(0,7.67$, and $40 \mathrm{~g} / 100 \mathrm{~kg}$ ) using a randomized block design in duplicate. Cheeses were then evaluated by descriptive and consumer sensory panels. Each consumer testing consisted of 120 panelists who were mainly 18 to 35 yr of age ( $>90 \%$ of total populace) with $>60 \%$ being frequent cheese consumers. Overall liking preference of the consumer group was for mild to medium cheese. Using the JAR scale, the medium cheeses were considered closest to JAR with a mean score of 3.0, compared with 2.4 for mild cheese and 3.6 for sharp cheese. Among low-fat cheeses, color was shown to be important with consumer liking being negatively influenced when the cheese appearance was too translucent (especially when normal levels of annatto were used) or too white. Matching the level of titanium dioxide with the annatto level gave the highest liking scores and flavor perception closest to JAR. This study established a significant effect of color on overall liking of low-fat versions of Cheddar cheese.
\end{abstract}

Key words: cheese, opacity, color, flavor

Received November 11, 2011.

Accepted January 1, 2012.

${ }^{1}$ Corresponding author: donald.mcmahon@usu.edu

\section{INTRODUCTION}

The color of food is an often overlooked sensory attribute that can actually change consumers' flavor perception. In case of cheese, flavor is an important attribute that affects consumer acceptance and marketing (Young et al., 2004; Yates and Drake, 2007). When likeable flavor notes are missing in low-fat cheeses, such as buttery, nutty, and milky attributes, the attention of consumers can be drawn to the cheese color and, thus, become a detriment to sales if the cheese color is outside the norm for cheese. Removing fat from cheese is known to impart a translucent appearance (Merrill et al., 1994; Paulson et al., 1998) and an increased intensity of color when annatto is added (Sipahioglu, et al., 1999). However, little information exists about choosing the amount of colorant to use and the effect of the color of cheese on consumer preference and buying decisions.

In general, coloring has been used in commercial food production to maintain the uniformity of products, and to enhance consumer appeal for the product. Some government agencies have color specifications for foods they purchase, such as for shredded Cheddar cheese in the United States: "if it is colored it needs to be medium yellow-orange with a uniform bright color, and an attractive sheen" (USDA, 2001). Likewise, for mandatory price reporting of cheese sales by manufacturers, the color of 40-lb blocks are required to be within the range of 6 to 8 on the National Cheese Institute (NCI) color chart (USDA, 2011). Adding color to cheese helps maintain a uniform color irrespective of whether the animals producing the milk are fed green pasture or a TMR of dried feedstuffs. In the United States, annatto extract is the permitted colorant for adding to cheese and is considered as being exempt from certification and is informally considered to be a natural color (FDA, 2011). It imparts a yellowish-orange color from its carotenoid components, bixin and norbixin.

It is important for food manufacturers to have the expected color in their food products because consumers associate certain colors with certain flavors. Color and appearance of food create expectations that affect what we feel and behave (Hutchings, 2003) and influences food identification (Delwiche, 2004). Judgments created on the basis of color can influence buying decisions 
and also carry over to cooking and eating decisions. Consequently, when food colors are different from the expected norm, flavor identification is decreased, the color-flavor association becomes stronger, and color has a greater effect on liking of the food (Roth et al., 1988). This occurs in simple foods and in complex foods in which there are multiple taste stimuli (Pangborn et al., 1963). For example, when white wine is colored red, the tendency is to describe the wine using red wine odor terms instead of the white wine odor terms that are instinctively used in uncolored wine (Morrot et al., 2001). However, to our knowledge no similar testing has been done on how cheese flavor is influenced by color.

Initial perception of foods occurs within the first 90 s of observation, and approximately 60 to $90 \%$ of the assessment is based on color (Singh, 2006). The color of cheese can be used for differentiating products from competitors, but it is important to be aware that consumer attitude can also be influenced by color (Singh, 2006). If cheese color is unacceptable, the other 2 important factors for consumer liking, flavor and texture of the cheese, are unlikely to be judged at all (Francis, 1995). This influence of color on food acceptability, choice, and preference comes more from learned associations than any inherent psychophysical characteristic (Clydesdale, 1993).

The aim of this study was to determine how the translucent appearance (color) of low-fat Cheddar cheese affects consumer acceptability and if increasing cheese opacity alters flavor perception. Different levels of annatto and titanium dioxide colorants were used to make low-fat cheese. Some mild, medium, and sharp full-fat Cheddar cheeses were used to establish the flavor preferences of the pool of consumers who performed sensory evaluation of the low-fat cheeses.

\section{MATERIALS AND METHODS}

\section{Full-Fat Cheese}

Two different brands of full fat commercial Cheddar cheese ( $\mathrm{A}=$ Kraft Foods Inc., Glenview, IL; $\mathrm{B}=$ Gossner Foods Inc., Logan, UT) labeled as mild, medium, and sharp were purchased from local grocery stores. We also selected mild (2 mo), medium (6 mo), and sharp (12 mo) cheeses from 2 Cheddar cheese types (C, D) manufactured by the Gary Haight Richardson Dairy Products Laboratory at Utah State University (USU, Logan). Cheese $\mathrm{C}$ is made for sale after 6-mo storage (including $2 \mathrm{mo}$ at $10^{\circ} \mathrm{C}$ ) and includes an adjunct Lactobacillus helveticus culture so it develops a sweet umami flavor. Cheese D is made for sale after 2 -yr storage at $6^{\circ} \mathrm{C}$ and is made with an adjunct Lactococcus lactis culture that increases levels of $2 / 3$-methyl butanal and 2-methyl propanal in cheese, resulting in increased nutty flavor (Carunchia Whetstine et al., 2006). After purchase and sampling, all cheeses were stored at $4^{\circ} \mathrm{C}$ until analyzed to minimize further flavor development.

\section{Low-Fat Cheese}

Nine batches of low-fat cheese with different color combinations (Table 1 ) were manufactured using a 3 $\times 3$ randomized block design, with all 9 cheeses being made within 3 consecutive days, in each of 2 separate replicates. Fresh milk was obtained from the George B. Caine Dairy Research and Teaching Center (Wellsville, UT) and then transported to the Gary H. Richardson Dairy Products Laboratory where the milk was standardized to a protein-fat ratio of 5.0 and pasteurized $\left(72^{\circ} \mathrm{C}\right.$ for $\left.15 \mathrm{~s}\right)$ and brought to $22^{\circ} \mathrm{C}$. Milk was acidified to $\mathrm{pH} 6.2$ using L-lactic acid (Nelson-Jameson Inc., Marshfield, WI), diluted (1:16) and titanium dioxide emulsion (Roha USA LLC, St. Louis, MO) added (0, 7.67 , or $40 \mathrm{~g} / 100 \mathrm{~kg}$ ). The milk was warmed to $35^{\circ} \mathrm{C}$, and then inoculated with $0.02 \%$ Lc. lactis culture as frozen pellets (DVS850; Chr. Hansen Inc., Milwaukee, WI) with continuous stirring. After $20 \mathrm{~min}$, single-strength annatto (DSM Foods Specialty Inc., Parsippany, NJ) was added at $0,7.34$, or $22 \mathrm{~g} / 100 \mathrm{~kg}$. Then, after a total of $30 \mathrm{~min}$ of ripening, the milk was set using $7.5 \mathrm{~g} / 100$ $\mathrm{kg}$ double-strength chymosin ( 650 international milk clotting U/mL; Chy-Max; Chr. Hansen Inc.). After 20 min, the curd was cut using $1.6-\mathrm{cm}$ spaced wire knives, healed for $5 \mathrm{~min}$, and then stirred for $40 \mathrm{~min}$; then, half of the whey was drained. Stirring continued until the curd reached $\mathrm{pH} 5.95$ and then the remaining whey was drained. The curd particles were dry stirred until reaching $\mathrm{pH} 5.50$ and then washed using $4^{\circ} \mathrm{C}$ cold water [ $50 \%$ (wt/wt) of curd] to lower the curd temperature to $22^{\circ} \mathrm{C}$. The curd was then weighed and salted using $22 \mathrm{~g} / \mathrm{kg}$ of curd applied in 3 applications, 5 min apart; then, the curd was filled into plastic hoops and pressed at $60 \mathrm{kPa}$ for $18 \mathrm{~h}$, vacuum packaged, and stored at $3^{\circ} \mathrm{C}$.

\section{Proximate Analysis}

Moisture content was determined in triplicate by weight loss using a microwave oven (CEM Corp., Indian trail, NC) at $100 \%$ power with an endpoint setting of $<0.4 \mathrm{mg}$ weight change over $2 \mathrm{~s}$. Fat content was determined in duplicate using a modified Babcock method (Richardson, 1985). Salt was measured by homogenizing grated cheese with distilled water for $4 \mathrm{~min}$ at $260 \mathrm{rpm}$ in a Stomacher 400 (Seward Ltd., Worthing, UK). The slurry was filtered through Whatman \#1 
Table 1. Low-fat cheese code based on amount of annatto and titanium dioxide added to milk before renneting

\begin{tabular}{lccc}
\hline & \multicolumn{3}{c}{ Titanium dioxide $^{2}$} \\
\cline { 2 - 4 } $\begin{array}{l}\text { Annatto } \\
(\mathrm{mg} / \mathrm{kg})\end{array}$ & $0 \mathrm{mg} / \mathrm{kg}$ & $76.7 \mathrm{mg} / \mathrm{kg}$ & $400 \mathrm{mg} / \mathrm{kg}$ \\
\hline 0 & 1 & 2 & 3 \\
73.4 & 4 & 5 & 6 \\
220 & 7 & 8 & 9 \\
\hline
\end{tabular}

${ }^{1}$ Single strength (DSM Specialties Inc., Parsippany, NJ).

${ }^{2}$ Titanium dioxide emulsion (Roha USA LLC, St. Louis, MO).

filter paper, and the filtrate was analyzed for sodium chloride using a chloride analyzer (model 926; Corning Inc., Medfield, MA). The $\mathrm{pH}$ was measured using a glass electrode after stomaching $20 \mathrm{~g}$ of grated cheese with $10 \mathrm{~g}$ of distilled water for $1 \mathrm{~min}$ at $260 \mathrm{rpm}$.

\section{Color Analysis}

Cheese color was measured using a MiniScan portable colorimeter (Hunter Associates Laboratory Inc., Reston, VA). Color standardization was performed using white and black standard plates (Hunter Associates Laboratory Inc.) inserted into a plastic bag (QME355 3.5 mil; Vilutis and Co. Inc., Frankfurt, IL) used for cheese packaging. Color measurements were made using Commission Internationale de l'Éclairage (CIE, 1978) $\mathrm{L}^{*}, \mathrm{a}^{*}$, and $\mathrm{b}^{*}$ values using illuminant D65. The $\mathrm{L}^{*}$ value is an indicator of luminosity (the degree of lightness from black to white). The $\mathrm{a}^{*}$ value is an indicator of green $(-)$ and red $(+)$, whereas $\mathrm{b}^{*}$ is an indicator of blue $(-)$ and yellow $(+)$. Because combining $\mathrm{a}^{*}$ and $\mathrm{b}^{*}$ gives a better indication of color than their individual values, we calculated hue angle as the inverse tangent of the ratio $b^{*} / a^{*}$ (HunterLab, 2011). The NCI cheese color standards were purchased from Nelson-Jameson Inc.

\section{Sensory Analysis of Flavor}

All sensory evaluation was conducted in compliance with the USU Institutional Review Board for human subjects' approval. For descriptive sensory analysis, cheeses were cut into 3.5 -cm cubes and then placed into soufflé cups $(58 \mathrm{~mL})$ covered with lids and numbered with randomly generated 3 -digit codes. The cheeses were tempered at $12^{\circ} \mathrm{C}$ for $1 \mathrm{~h}$ and were served at this temperature with deionized water and unsalted crackers for palate cleansing. A trained descriptive sensory panel (n $=9: 4$ female, 5 male, ages 22 to $50 \mathrm{yr}$ ), with $>150 \mathrm{~h}$ of training in descriptive analysis of cheese flavor, evaluated the cheeses. Separate evaluations were performed under red light and white light using a 0 - to 15-point universal intensity scale described by Meilgaard et al.
(2007). Cheese flavor lexicon terms of cooked, whey, FFA, rosy/floral, bitter, salty, sweet, sour, and umami were referenced as described by Drake et al. (2001). Reference identities for fruity, nutty, brothy and sulfur, and pineappley were modified from Drake et al. (2001) to frozen apple/grape/peach juice concentrate blend, hazelnut extract, low-sodium chicken broth, $\mathrm{H}_{2} \mathrm{~S}$ (400 $\mu \mathrm{g} / \mathrm{kg}$ in water or skim milk), and frozen pineapple juice concentrate, respectively. Reference identities for buttery was melted butter homogenized into warm milk, for oxidized was pasteurized non-homogenized milk treated with $2 \mathrm{mg}$ of copper sulfate/ $\mathrm{kg}$ for $1 \mathrm{wk}$ at $4^{\circ} \mathrm{C}$, and milky was referenced based on Meilgaard et al. (2007) using whole milk compared with skim milk. Each cheese sample was tasted twice by each panelist in each evaluation on the same day, with a 30-min break between taste sessions. Evaluations were conducted individually using SIMS 2000 (Sensory Computer Systems, Morristown, NJ) in an enclosed room free from external aromas, noise, and distractions. Panelists were instructed to expectorate samples after evaluation. If mean attribute scores were $\leq 0.5$, the attribute was considered not detectable (ND).

\section{Consumer Preference Testing}

A series of consumer tests were conducted with each panel consisting of approximately 120 participants, 18 to 65 y of age, who were recruited via website, newspaper advertisements, and flyers. The consumer participants were approved on the basis of legal age (18 and above) and absence of food allergies and, in general, included university faculty, staff, and students. Testing by the consumers was in individual booths with standard white lighting and entering their responses using SIMS 2000 software including space for open comments. Cheese blocks were cut into $2.5-\mathrm{cm}$ cubes and served to them on a plate along with water.

Cheeses were evaluated for color and overall liking using a 9-point hedonic scale (with $1=$ extremely dislike, $5=$ neither like nor dislike, and $9=$ extremely like), and for cheese sharpness, flavor, and chewiness, a just-about-right (JAR) 5-point agreement scale was used with the center point being just about right, where $1=$ not enough attribute and $5=$ too much of the attribute. Each participant was rewarded with a coupon for a free ice cream after their complete responses in each panel.

Full-Fat Cheeses. With 12 cheeses to test, 2 panels were conducted with 6 cheeses presented to each panel. Consumer participants could attend one or both panels held on consecutive days. At the start of each panel, the consumers completed a questionnaire regarding their demographics, cheese consumption, cheese flavor 
preference (mild, medium, sharp, or extra sharp), frequency and intent of purchase for reduced- or low-fat cheeses, or both, and their willingness to pay more for low-fat cheeses.

Low-Fat Cheese. Consumers were informed that they would be evaluating cheese but not that it was low fat; however, they were asked questions about their consumption and willingness to purchase low- or reduced-fat cheese. Testing was performed using 2 panels of 120 consumers on different days in which they were presented with a plate containing 6 of the 9 low-fat cheeses, randomly organized so that each cheese was evaluated 80 times. Consumers were allowed to attend one or both panels.

\section{Statistical Analysis}

Mean scores for cheese consumer liking were analyzed using PROC GLM ANOVA based upon a randomized block design (SAS Institute, 1999). Evaluation of consumer preferences and full-fat cheeses was conducted once, with the 4 different brands acting as pseudoreplicates. Descriptive analysis of cheese was analyzed using split plot design with the PROC MIXED model of SAS. The 2 replicates of low-fat cheese were considered as blocks (random factor) and judges were considered as whole plot (random factor); annatto and $\mathrm{TiO}_{2}$ were treated as split plot (fixed factor). Differences were considered significant when resultant $P$-values were $<0.05$ (SAS Institute, 1999). The JAR sensory data were analyzed using the non-parametric Kruskal-Wallis test using the chi-squared distribution. The 5-point bipolar JAR scale was transformed to a 3-point ranking scale where 1 = bad (categories 1 and 5 of JAR scale combined, indicating the unacceptability of cheese attribute), 2 = fair (categories 2 and 4 combined), and 3 = good (just right). When treatments were significant, means were compared using the Tukey-Kramer multiple comparisons procedure.

\section{RESULTS}

\section{Full-Fat Cheese}

Cheese Composition. Mean moisture content of full-fat cheeses ranged from 36.3 to $39.5 \%$ (Table 2), with medium and sharp cheeses typically having lower moisture than mild cheeses. This was expected because long-hold cheeses are manufactured with less moisture to improve flavor development during aging, whereas short-hold cheeses are made with higher moisture to maximize yields. The one exception was cheese C, which was manufactured at USU for sale as an aged cheese and sampled after 2, 4, and 12 mo of storage. Fat content (30.5 to $33.5 \%)$, salt (1.9 to $2.1 \%)$, and $\mathrm{pH}(5.0$ to 5.3) were all within the normal range for Cheddar cheese.

Color. The commercial cheeses had a pronounced opaqueness with a matt surface appearance that is typical of full-fat Cheddar cheeses (Figure 1b). Color intensities of these cheeses varied and could be described as white, pale, and yellow-orange. Among the full-fat

Table 2. Mean composition and Hunter color $\left(\mathrm{L}^{*}, \mathrm{a}^{*}\right.$, and $\left.\mathrm{b}^{*}\right)$ values ${ }^{1}$ of full-fat Cheddar cheeses ${ }^{2}$

\begin{tabular}{|c|c|c|c|c|c|c|c|c|}
\hline Cheese & Moisture (\%) & Fat (\%) & Salt (\%) & $\mathrm{pH}$ & \multicolumn{3}{|c|}{ Hunter color } & $\begin{array}{c}\text { Hue } \\
\text { angle }^{3}\left({ }^{\circ}\right)\end{array}$ \\
\hline \multicolumn{9}{|l|}{ Mild } \\
\hline B & 38.9 & 31.5 & 2.0 & 5.1 & $49.5^{\mathrm{d}}$ & $12.4^{\mathrm{a}}$ & $26.5^{\mathrm{b}}$ & $63.1^{\mathrm{a}}$ \\
\hline $\mathrm{C}$ & 36.8 & 32.0 & 1.9 & 5.3 & $55.3^{\mathrm{c}}$ & $10.9^{\mathrm{ab}}$ & $25.6^{\mathrm{b}}$ & $68.8^{\mathrm{a}}$ \\
\hline $\mathrm{D}$ & 39.5 & 30.5 & 2.1 & 5.2 & $75.6^{\mathrm{a}}$ & $8.9^{\mathrm{bc}}$ & $7.3^{\mathrm{d}}$ & $40.1^{\mathrm{b}}$ \\
\hline C & 36.5 & 31.0 & 1.9 & 5.2 & $57.8^{\mathrm{c}}$ & $12.3^{\mathrm{a}}$ & $24.3^{\mathrm{bc}}$ & $63.1^{\mathrm{a}}$ \\
\hline $\mathrm{D}$ & 37.3 & 31.0 & 2.1 & 5.2 & $72.4^{\mathrm{a}}$ & $7.7^{\mathrm{d}}$ & $9.2^{\mathrm{d}}$ & $51.6^{\mathrm{b}}$ \\
\hline \multicolumn{9}{|l|}{ Sharp } \\
\hline A & 36.4 & 31.9 & 1.9 & 5.1 & $68.8^{\mathrm{b}}$ & $9.7^{\mathrm{b}}$ & $29.3^{\mathrm{a}}$ & $74.5^{\mathrm{a}}$ \\
\hline B & 37.0 & 32.8 & 2.1 & 5.0 & $51.2^{\mathrm{d}}$ & $12.4^{\mathrm{a}}$ & $24.9^{\mathrm{bc}}$ & $63.1^{\mathrm{ab}}$ \\
\hline $\mathrm{C}$ & 36.3 & 30.5 & 2.0 & 5.3 & $56.3^{\mathrm{c}}$ & $11.3^{\mathrm{ab}}$ & $22.3^{\mathrm{c}}$ & $63.1^{\mathrm{ab}}$ \\
\hline
\end{tabular}

\footnotetext{
${ }^{\mathrm{a}-\mathrm{d}}$ Color means in the same column with same superscript were not significantly different $(\alpha=0.05)$.
}

${ }^{1}$ The $\mathrm{L}^{*}$ value is an indicator of luminosity (the degree of lightness from black to white). The $\mathrm{a}^{*}$ value is an indicator of green $(-)$ and red $(+)$, whereas $\mathrm{b}^{*}$ is an indicator of blue $(-)$ and yellow $(+)$.

${ }^{2}$ Retail cheeses of A) Kraft Foods (Glenview, IL), B) Gossner Foods (Logan, UT), and manufactured at Utah State University (Logan) as C) Old Juniper and D) White Pine.

${ }^{3}$ Calculated as $\arctan \left(\mathrm{b}^{*} / \mathrm{a}^{*}\right)$. 
cheeses, cheese $\mathrm{B}$ and $\mathrm{C}$ had the most orange color as shown by having the highest $\mathrm{a}^{*}$ value $(P<0.05)$. Cheese A was more yellow in appearance (i.e., highest $b^{*}$ value) and lacked redness (i.e., low $a^{*}$ value). All of these were made with the addition of annatto or other colorant. In contrast, cheese D was made without any color being added and was lowest in yellow color intensity ( $\mathrm{b}^{*}=7$ to 9 ), with a similar degree of redness as cheese A (mean a* value of 8.2 compared with 9.3 for cheese A).

As expected, $\mathrm{L}^{*}$ values were highest $(P<0.05)$ for the uncolored cheese D (Table 2). Hue angle values for cheeses $\mathrm{A}, \mathrm{B}$, and $\mathrm{C}$ were not significantly different and ranged from 63 to $75^{\circ}$, which is within the expected values of 40 to $90^{\circ}$ transition from orange to yellow (as shown in Figure 1a). Cheese D had a lower $(P<0.05)$ hue angle of 40 to $52^{\circ}$. Although when colors are close to neutral, small variations can cause a large change in the calculated hue angle (HunterLab, 2011).

Flavor. Sensory attributes for full-fat cheeses that scored $>0.5$ (for at least 1 cheese) by the descriptive flavor panel are presented in Table 3. Cooked, whey, oxidized, fruity, pineappley, sulfur, and rosy/floral flavor attributes were ND in all cheeses. Attributes with the highest scores were salty (3.9 to 5.7 ), sour (1.9 to 4.7 ), milky (1.1 to 2.2 ), and umami (0.7 to 2.9). Some flavor attributes (bitter, FFA, brothy, nutty, and umami) all had a trend for increased intensity with advancement of cheese age. However, other attributes, including salty, sour, sweet, sulfur, whey, milky and buttery, did not follow any trend with cheese age. For cheeses A and $\mathrm{B}$, this may be a result of how these manufacturers selected cheeses to be sold as mild, medium, or sharp and we did not have any information on the aging or storage conditions for these cheeses. However, the ages of cheeses $\mathrm{C}$ and $\mathrm{D}$ were known and were aged for 2,6 , and 12 mo for mild, medium, and sharp, respectively. These cheeses showed a trend $(P=0.07)$ for increased bitterness with age (e.g., cheese C: mild $=\mathrm{ND}$, medium $=0.97$, and sharp $=1.06$ ), probably because of various metabolites generated during proteolysis of the cheese during aging (Marsili, 1985).

Consumer Preference. Demographics of consumers who participated in this study and their cheese consumption, preferences, and purchasing habits are shown in (Table 4). Most (95.7\%) of the panelists in the study were 18 to $35 \mathrm{yr}$ old, and all were cheese eaters. When asked their cheese flavor preference, most stated a preference for medium cheese (combined scores for extremely preferred and very preferred of 85, 54, and $47 \%$ for medium, sharp, and mild cheeses, respectively) with extra sharp cheese being least preferred (Figure 2). However, during actual taste testing, the mild cheese category (averaged for all 4 cheeses A, B,

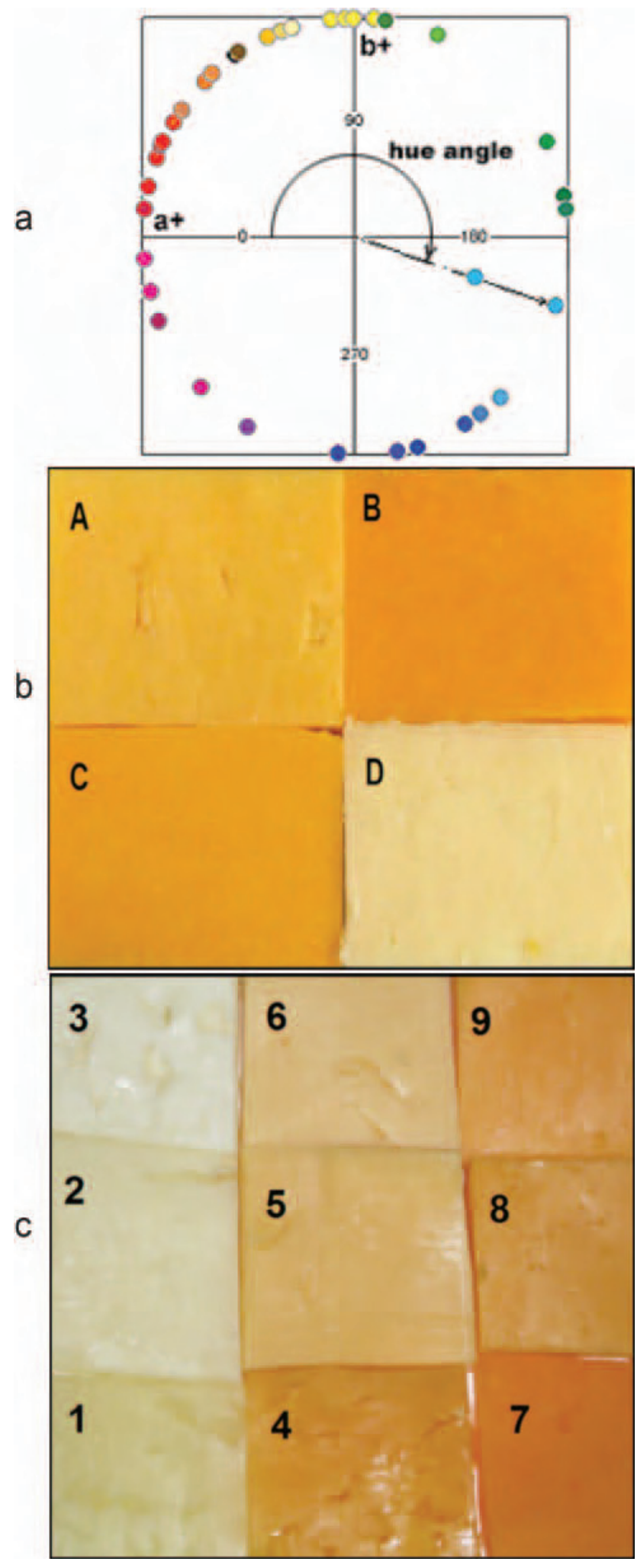

Figure 1. (a) Color representation of hue angle and color comparison of (b) 4 commercial full-fat Cheddar cheeses A, B, C, and D (as described in Table 2), and (c) 9 low-fat cheeses 1 to 9 made using different levels of annatto and titanium dioxide (as described in Table 1). Figure 1a reprinted with permission from MacEvoy (2009). 
Table 3. Sensory flavor attributes ${ }^{1}$ of full-fat Cheddar cheeses ${ }^{2}$ designated by the manufacturer as being mild, medium (Med), or sharp

\begin{tabular}{|c|c|c|c|c|c|c|c|c|c|c|c|c|c|}
\hline Attribute & \multicolumn{12}{|c|}{ Sensory attribute } & $P$-value \\
\hline Milky & $2.14^{\mathrm{a}}$ & $1.11^{\mathrm{b}}$ & $1.64^{\mathrm{ab}}$ & $2.06^{\mathrm{ab}}$ & $1.22^{\mathrm{ab}}$ & $2.17^{\mathrm{a}}$ & $1.25^{\mathrm{ab}}$ & $1.56^{\mathrm{ab}}$ & $1.22^{\mathrm{ab}}$ & $1.83^{\mathrm{ab}}$ & $1.61^{\mathrm{ab}}$ & $1.28^{\mathrm{ab}}$ & 0.04 \\
\hline Buttery & 0.75 & 0.69 & $\mathrm{ND}^{3}$ & 1.11 & 1.11 & 0.83 & 1.03 & 0.75 & ND & 1.17 & $\mathrm{ND}$ & 0.61 & 0.16 \\
\hline FFA & $\mathrm{ND}^{\mathrm{bc}}$ & $0.86^{\mathrm{ab}}$ & $1.22^{\mathrm{a}}$ & $\mathrm{ND}^{\mathrm{bc}}$ & $\mathrm{ND}^{\mathrm{bc}}$ & $0.72^{\mathrm{abc}}$ & $\mathrm{ND}^{\mathrm{bc}}$ & $0.75^{\mathrm{abc}}$ & $0.75^{\mathrm{abc}}$ & $\mathrm{ND}^{\mathrm{c}}$ & $1.06^{\mathrm{a}}$ & $0.72^{\mathrm{abc}}$ & $<0.01$ \\
\hline Sweet & 0.56 & ND & ND & 0.56 & 0.61 & 0.78 & 0.83 & 0.75 & 0.67 & 1.67 & 0.94 & 0.67 & 0.17 \\
\hline Sour & $2.86^{\text {cde }}$ & $3.58^{\mathrm{abc}}$ & $4.72^{\mathrm{a}}$ & $3.22^{\text {bcde }}$ & $3.5^{\mathrm{abc}}$ & $4.44^{\mathrm{ab}}$ & $2.06^{\mathrm{de}}$ & $2.83^{\text {cde }}$ & $2.69^{\text {cde }}$ & $1.89^{\mathrm{e}}$ & $3.83^{\mathrm{abc}}$ & $3.33^{\mathrm{abcd}}$ & $<0.01$ \\
\hline Salty & 3.89 & 4.97 & 5.03 & 4.39 & 4.78 & 5.67 & 4.17 & 4.72 & 4.56 & 4.11 & 4.17 & 4.78 & 0.13 \\
\hline Bitter & ND & 0.81 & 0.81 & 1.06 & 1.00 & 1.06 & ND & 0.97 & 1.06 & ND & 1.00 & 1.00 & 0.07 \\
\hline Umami & $0.78^{\mathrm{c}}$ & $1.33^{\mathrm{bc}}$ & $1.39^{\mathrm{bc}}$ & $0.72^{\mathrm{c}}$ & $1.17^{\mathrm{bc}}$ & $2.78^{\mathrm{a}}$ & $0.97^{\mathrm{bc}}$ & $1.72^{\mathrm{bc}}$ & $1.97^{\mathrm{ab}}$ & $2.06^{\mathrm{ab}}$ & $2.06^{\mathrm{ab}}$ & $2.89^{\mathrm{a}}$ & $<0.01$ \\
\hline
\end{tabular}

${ }^{\mathrm{a} e}$ Means within the same row with same superscript were not significantly different $(\alpha=0.05)$.

${ }^{1}$ Attributes were scored using a 0- to 15-point universal intensity scale (Meilgaard et al., 2007) using an established cheese flavor language (Drake et al., 2001; Drake, 2007). Most cheese flavor attributes fall between 0 and 5 on this scale (Drake et al., 2008a,b, 2009).

${ }^{2}$ Retail cheeses of (A) Kraft Foods (Glenview, IL), (B) Gossner Foods (Logan, UT), and manufactured at Utah State University (Logan) as (C) Old Juniper and (D) White Pine.

${ }^{3}$ Flavor attribute not detected (ND) by any panelist.

$\mathrm{C}$, and D) received slightly higher overall liking scores (6.45 compared with 6.22 for medium; Table 5). The sharp cheeses were rated lowest $(P<0.05)$.

Using the attributes diagnostic test, significant differences $(P<0.001)$ were found among the cheeses for sharpness, flavor, and chewiness. Participants demonstrated they understood the difference between a mild and sharp cheese because when asked to rate sharpness using the JAR scale, mild and medium cheeses received mean scores of 1.5 and 2.4, respectively, and sharp cheeses $\mathrm{A}, \mathrm{B}$, and $\mathrm{C}$ were considered just about right, with scores of 2.8 to 2.9. Interestingly, sharp cheese D

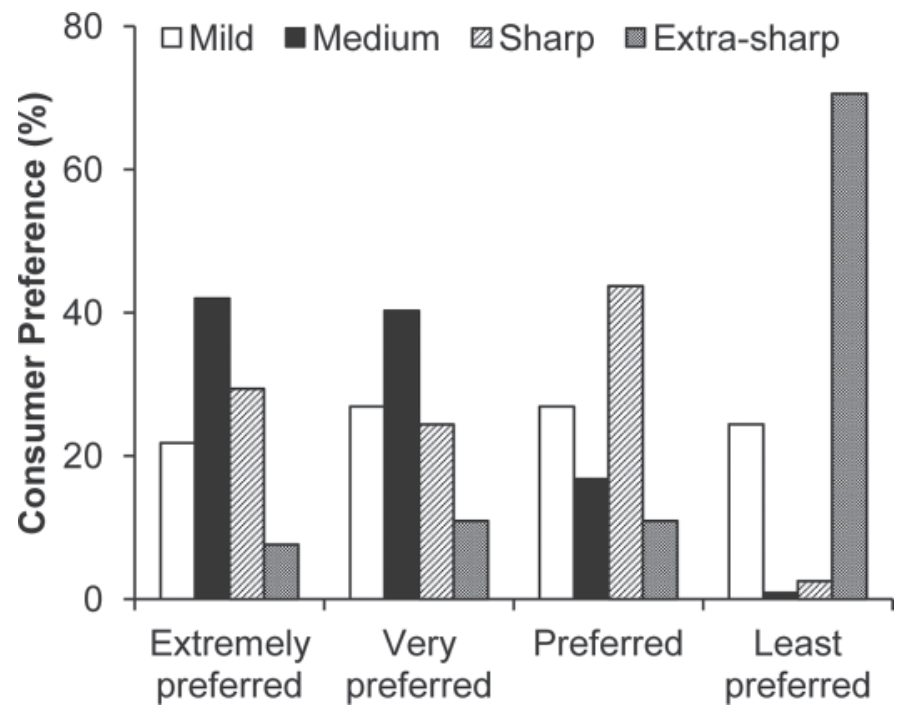

Figure 2. Percentagewise distribution of stated consumer preference for mild, medium, sharp, and extra-sharp cheeses.
Table 4. Demographic information and consumer characteristics of consumer panelists

\begin{tabular}{lc}
\hline Question & Response $(\%)$ \\
\hline Sex & \\
Male & 52.5 \\
Female & 47.5 \\
Age (yr) & \\
18 to 25 & 71.7 \\
26 to 35 & 19.2 \\
36 to 45 & 2.5 \\
46 to 55 & 3.3 \\
>56 & 3.3 \\
Cheese purchasing frequency & \\
Never & 0.0 \\
Less than once per month & 1.7 \\
At least once per month & 0.8 \\
At least once per week & 33.3 \\
About once per day & 52.5 \\
More than once per day & 11.7 \\
How cheese is used & \\
Snacking & 80.8 \\
Sandwiches & 91.7 \\
Pasta & 65.0 \\
Pizza & 91.7 \\
Hamburgers & 70.8 \\
Salad & 53.3 \\
Other & 40.0 \\
Form of cheese purchased & \\
Block & \\
Sliced & \\
Shredded & 65.0 \\
Perceived fat content of cheese & 11.7 \\
0 to 10\% & 25.0 \\
11 to 20\% & \\
21 to 30\% & 7.5 \\
41 to 40\% $50 \%$ & 28.3 \\
Do you purchase reduced-fat cheese? & 29.2 \\
No & 28.3 \\
Yes & 6.7 \\
\hline & 86.7 \\
\hline & 13.3 \\
\hline
\end{tabular}


Table 5. Mean consumer overall and color liking and just-about-right (JAR) responses for cheese sharpness, flavor, and chewiness for commercial full-fat cheeses ${ }^{1}$

\begin{tabular}{|c|c|c|c|c|c|}
\hline \multirow[b]{2}{*}{ Cheese } & \multicolumn{2}{|c|}{ Liking $^{2}$} & \multicolumn{3}{|c|}{$\mathrm{JAR}^{3}$} \\
\hline & Overall & Color & Sharpness & Flavor & Chewiness \\
\hline \multicolumn{6}{|l|}{ Mild } \\
\hline A & $6.8^{\mathrm{a}}$ & $7.3^{\mathrm{a}}$ & $1.6^{\mathrm{c}}$ & $2.3^{\mathrm{d}}$ & $2.8^{\mathrm{ab}}$ \\
\hline B & $6.1^{\mathrm{b}}$ & $6.8^{\mathrm{ab}}$ & $1.6^{\mathrm{c}}$ & $2.4^{\mathrm{d}}$ & $3.0^{\mathrm{a}}$ \\
\hline $\mathrm{C}$ & $6.4^{\mathrm{ab}}$ & $7.2^{\mathrm{a}}$ & $1.5^{\mathrm{c}}$ & $2.6^{\mathrm{c}}$ & $2.9^{\mathrm{a}}$ \\
\hline $\mathrm{D}$ & $6.5^{\mathrm{ab}}$ & $7.1^{\mathrm{a}}$ & $1.4^{\mathrm{d}}$ & $2.3^{\mathrm{d}}$ & $2.9^{\mathrm{a}}$ \\
\hline \multicolumn{6}{|l|}{ Medium } \\
\hline A & $6.1^{\mathrm{b}}$ & $7.2^{\mathrm{a}}$ & $1.8^{\mathrm{c}}$ & $2.5^{\mathrm{d}}$ & $2.7^{\mathrm{bc}}$ \\
\hline B & $6.5^{\mathrm{a}}$ & $6.5^{\mathrm{ab}}$ & $2.3^{\mathrm{b}}$ & $3.1^{\mathrm{c}}$ & $2.9^{\mathrm{ab}}$ \\
\hline $\mathrm{C}$ & $6.2^{\mathrm{bc}}$ & $7.0^{\mathrm{a}}$ & $2.3^{\mathrm{b}}$ & $3.3^{\mathrm{b}}$ & $2.8^{\mathrm{ab}}$ \\
\hline $\mathrm{D}$ & $6.1^{\mathrm{bc}}$ & $6.7^{\mathrm{ab}}$ & $2.4^{\mathrm{b}}$ & $3.2^{\mathrm{b}}$ & $2.7^{\mathrm{bc}}$ \\
\hline \multicolumn{6}{|l|}{ Sharp } \\
\hline A & $5.9^{\mathrm{bc}}$ & $7.4^{\mathrm{a}}$ & $2.8^{\mathrm{a}}$ & $3.8^{\mathrm{a}}$ & $2.5^{\mathrm{c}}$ \\
\hline B & $4.9^{\mathrm{d}}$ & $6.1^{\mathrm{b}}$ & $2.8^{\mathrm{a}}$ & $3.4^{\mathrm{b}}$ & $2.7^{\mathrm{bc}}$ \\
\hline $\mathrm{C}$ & $5.4^{\mathrm{c}}$ & $6.9^{\mathrm{a}}$ & $2.9^{\mathrm{a}}$ & $3.7^{\mathrm{a}}$ & $2.9^{\mathrm{a}}$ \\
\hline $\mathrm{D}$ & $5.6^{\mathrm{c}}$ & $7.2^{\mathrm{a}}$ & $2.5^{\mathrm{b}}$ & $3.4^{\mathrm{b}}$ & $2.7^{\mathrm{bc}}$ \\
\hline
\end{tabular}

${ }^{a-d}$ Means in the same column with the same letter were not significantly different $(\alpha=0.05)$.

${ }^{1}$ Retail cheeses of A) Kraft Foods (Glenview, IL), B) Gossner Foods (Logan, UT), and manufactured at Utah State University (Logan) as C) Old Juniper and D) White Pine. These cheeses are described in Table 2.

${ }^{2}$ Evaluated using 9 -point hedonic scale, where $9=$ like extremely, $5=$ neither like nor dislike, and $1=$ dislike extremely

${ }^{3}$ Evaluated using a 5 -point JAR scale, where $1=$ not enough attribute, $3=$ just about right, and $5=$ too much attribute.

was perceived as lacking sharpness $(\mathrm{JAR}$ score $=2.5)$, even though it was the same age as sharp cheese C. However, there was a difference in how they were aged. Cheese $\mathrm{C}$ was made using an adjunct $L b$. helveticus culture and was subject to accelerated cheese ripening with 10 -wk storage at $10^{\circ} \mathrm{C}$, whereas cheese $\mathrm{D}$ was maintained continuously at $6^{\circ} \mathrm{C}$.

Overall, the sharp cheeses were considered as having too much flavor with mean JAR scores of 3.4 to 3.8, and the mild cheeses were considered to have too little flavor (JAR scores of 2.3 to 2.6). The full-fat cheeses that were considered closest to being just about right in flavor were the medium cheeses (JAR scores of 2.5 to 3.3). For overall liking (using the hedonic scale), the mean scores decreased with cheese sharpness level and for mild, medium, and sharp cheeses were $6.45,6.22$, and 5.45 , respectively (Table 5).

\section{Low-Fat Cheese}

Composition. All of the low-fat cheeses were made using the same procedure and milk with similar proteinfat ratio and had 5 to $6.5 \%$ fat, 52 to $55 \%$ moisture, 1.8 to $1.9 \%$ salt, and a $\mathrm{pH}$ of 5.0 to 5.5 . At this moisture level, the low-fat cheeses have a similar initial firmness to full-fat cheeses, achieved by using pre-acidification of milk before renneting and eliminating cooking of the curd.

Color. Orange color intensity of the low-fat cheeses increased with amount of annatto used, as shown by an increase in both red $\left(\mathrm{a}^{*}\right)$ and yellow ( $\mathrm{b}^{*}$; Table 6$)$. Cheese made without any annatto (cheeses 1,2 , and 3) had similar low a* $(-2.5 \pm 0.2$, indicating a slight green tinge) and $b^{*}$ values $(7 \pm 2)$, indicating a slight yellow color. Cheeses 7, 8, and 9 with the highest annatto had the highest $\mathrm{a}^{*}$ and $\mathrm{b}^{*}$ values $(15 \pm 0.5$ and $42 \pm 7$, respectively). Cheeses made using $7.34 \mathrm{~mL}$ of annatto $/ 100 \mathrm{~kg}$ (the level used at USU to manufacture Old Juniper Cheddar cheese) had intermediate $a^{*}$ and $\mathrm{b}^{*}$ values $(7.2 \pm 0.3$ and $33 \pm 2$, respectively). Interestingly, cheese 8 , where annatto was combined with the intermediate level of titanium dioxide, had the highest $b^{*}$ value of 48.7 , indicating a synergistic effect of increasing whiteness on enhancing the yellow appearance of low-fat cheese. Cheese 8 was also the low-fat cheese that matched the US Department of Agriculture cheese color specification the best, with $\mathrm{L}^{*}, \mathrm{a}^{*}$, and $\mathrm{b}^{*}$ values and hue angle of $67.3,14.9,48.7$, and 73 compared with NCI cheese color 6 , with corresponding values of 79.0 , $14.8,50.8$, and 73.9 , respectively.

Addition of titanium dioxide eliminated the translucent appearance characteristic of low-fat and nonfat cheeses (Paulson et al., 1998; Dave et al., 2001). The low-fat cheeses with no titanium dioxide added (cheeses $1,4$, and 7$)$ all had low $\mathrm{L}^{*}$ values $(52 \pm 5)$ and among the others, cheese 3 had the highest $\mathrm{L}^{*}$ value of 84 (Table 6). Cheeses 6 and 9 with the same level of titanium dioxide as cheese 3 were less noticeably white and their $\mathrm{L}^{*}$ values decreased with increasing annatto $(73.9$ and 65.0 , respectively). All of the low-fat cheeses made 
Table 6. Mean Hunter color $\left(\mathrm{L}^{*}, \mathrm{a}^{*}\right.$, and $\left.\mathrm{b}^{*}\right)$ values ${ }^{1}$ and hue angle of experimental low-fat cheeses

\begin{tabular}{lcccc}
\hline & \multicolumn{3}{c}{ Hunter color } & \\
\cline { 2 - 4 } Cheese $^{2}$ & $\mathrm{~L}^{*}$ & $\mathrm{a}^{*}$ & $\mathrm{~b}^{*}$ & $\begin{array}{c}\text { Hue } \\
\text { angle }^{3}\left({ }^{\circ}\right)\end{array}$ \\
\hline 1 & $56.6^{\mathrm{d}}$ & -2.7 & $4.6^{\mathrm{d}}$ & $-{ }^{4}$ \\
2 & $71.0^{\mathrm{b}}$ & -2.43 & $7.8^{\mathrm{d}}$ & - \\
3 & $83.9^{\mathrm{a}}$ & -2.5 & $8.9^{\mathrm{d}}$ & - \\
4 & $52.1^{\mathrm{d}}$ & $7.4^{\mathrm{b}}$ & $31.9^{\mathrm{bc}}$ & $76.9^{\mathrm{a}}$ \\
5 & $74.2^{\mathrm{b}}$ & $7.0^{\mathrm{b}}$ & $34.7^{\mathrm{b}}$ & $78.6^{\mathrm{a}}$ \\
6 & $73.9^{\mathrm{b}}$ & $7.5^{\mathrm{b}}$ & $31.1^{\mathrm{b}}$ & $76.4^{\mathrm{a}}$ \\
7 & $46.6^{\mathrm{e}}$ & $14.6^{\mathrm{a}}$ & $37.8^{\mathrm{b}}$ & $68.9^{\mathrm{a}}$ \\
8 & $67.3^{\mathrm{c}}$ & $14.9^{\mathrm{a}}$ & $48.7^{\mathrm{a}}$ & $73.0^{\mathrm{a}}$ \\
9 & $65.0^{\mathrm{c}}$ & $15.4^{\mathrm{a}}$ & $40.7^{\mathrm{a}}$ & $69.3^{\mathrm{a}}$ \\
\hline
\end{tabular}

${ }^{\mathrm{a} e} \mathrm{Means}$ in the same column with same letter were not significantly different $(\alpha=0.05)$.

${ }^{1}$ The $\mathrm{L}^{*}$ value is an indicator of luminosity (the degree of lightness from black to white). The $\mathrm{a}^{*}$ value is an indicator of green $(-)$ and red $(+)$, whereas $\mathrm{b}^{*}$ is an indicator of blue $(-)$ and yellow $(+)$.

${ }^{2}$ Low-fat cheeses made with varying levels of annatto and titanium dioxide.

${ }^{3}$ Calculated as $\arctan \left(\mathrm{b}^{*} / \mathrm{a}^{*}\right)$.

${ }^{4}$ Not appropriate to calculate hue values for neutral colors [i.e., when $\sqrt{ }\left(\mathrm{a}^{* 2}+\mathrm{b}^{* 2}\right) \sim 5$ or less (HunterLab, 2011)].

with annatto had similar hue angels $\left(74 \pm 5^{\circ}\right)$, that was most similar to full-fat cheese A (hue angle $=71$ to $74^{\circ}$ ). This was the cheese that was the most orange in color and had the highest $b^{*}$ value.

When considered on a visual basis (as shown in Figure 1c), the lack of opaqueness in cheeses 1, 4, and 7 was very apparent, and the annatto-colored cheeses appeared too orange in color and had a rubbery appearance. With the combination of annatto and titanium dioxide, the low-fat cheeses appeared to be closer to what is expected for Cheddar cheese. Although with the highest usage level of titanium dioxide and midrange usage of annatto (i.e., cheese 6), the cheese ap- peared pale and more similar to process cheese rather than a natural Cheddar cheese.

Flavor. As the only difference in the low-fat cheeses was the addition of color, they were expected to be similar in flavor. When evaluated by the descriptive panelists, this was the case for all flavor attributes except bitter (Table 7). The order of predominance of flavor attributes was salty (3.4 to 4.7), sour (1.9 to 2.9 ), brothy (1.8 to 2.6$)$, umami (1.4 to 1.8$)$, milky (1.0 to 1.7 ), bitter (ND to 1.9), buttery (ND to 0.8 ), nutty (ND to 0.6), and sweet (ND to 0.6). The panelists also detected a slight burnt flavor in these cheeses that is common in low-fat cheeses. The lowest bitter attribute scores were for cheeses 3,4 , and 5 (bitter score $=$ ND to 0.8$)$, and these were significantly different $(P<0.05)$ from cheeses $1,2,6,7$, and 9 (bitter score $=1.5$ to 1.9). No overall trend was apparent based on the level of annatto or level of titanium dioxide.

Consumer Evaluation. Mean consumer scores for overall liking, color, sharpness, flavor, and chewiness are shown in Table 8. As the cheeses were evaluated under white light, it was apparent to the panelists that the cheeses had distinct differences in color (as shown in Figure 1c). Cheese 7, which had a dark orange translucent appearance, received the lowest $(P<0.05)$ overall liking score (4.3; i.e., slightly disliked). It also was most disliked (4.2) for color. The other cheeses that had no titanium dioxide added (cheeses 1 and 4) and, therefore, also had the translucent appearance typical of low-fat cheese received the next lowest $(P<0.05)$ overall liking scores (5.9 and 5.6, respectively). A positive correlation $(\mathrm{r}=0.40, P<0.05)$ was observed between overall liking and color liking (data not shown).

Cheese 5 (made using intermediate levels of both annatto and titanium dioxide) received the highest scores

Table 7. Sensory flavor attributes for low-fat cheeses made using different levels of annatto and titanium dioxide colorants

\begin{tabular}{|c|c|c|c|c|c|c|c|c|c|}
\hline Item & \multicolumn{9}{|c|}{ Attribute $^{1}$} \\
\hline \multicolumn{10}{|l|}{ Cheese $^{2}$} \\
\hline 2 & 1.69 & ND & 2.16 & 0.59 & ND & 2.94 & 4.41 & $1.69^{\mathrm{a}}$ & 1.81 \\
\hline 3 & 1.22 & 0.75 & 2.19 & ND & ND & 2.00 & 3.59 & $\mathrm{ND}^{\mathrm{b}}$ & 1.38 \\
\hline 4 & 1.13 & 0.78 & 1.84 & ND & 0.59 & 2.16 & 3.63 & $0.75^{\mathrm{b}}$ & 1.44 \\
\hline 8 & 1.25 & 0.69 & 2.19 & ND & ND & 1.97 & 4.09 & $1.09^{\mathrm{ab}}$ & 1.63 \\
\hline 9 & 1.31 & ND & 2.47 & ND & ND & 3.28 & 4.66 & $1.94^{\mathrm{a}}$ & 1.59 \\
\hline$P$-value & 0.984 & 0.903 & 0.943 & 0.995 & 0.911 & 0.141 & 0.962 & 0.026 & 0.987 \\
\hline
\end{tabular}

\footnotetext{
${ }^{a, b}$ Means within the same column with the same letter were not significantly different $(\alpha=0.05)$.

${ }^{1}$ Evaluated using a 15-point scale, as described by Meilgaard et al. (2007).

${ }^{2}$ Cheeses are as described in Table 1.

${ }^{3} \mathrm{ND}=$ not detected.
} 
Table 8. Mean consumer overall and color liking and just-about-right (JAR) responses for cheese sharpness, flavor, and chewiness for low-fat cheeses with different color profiles

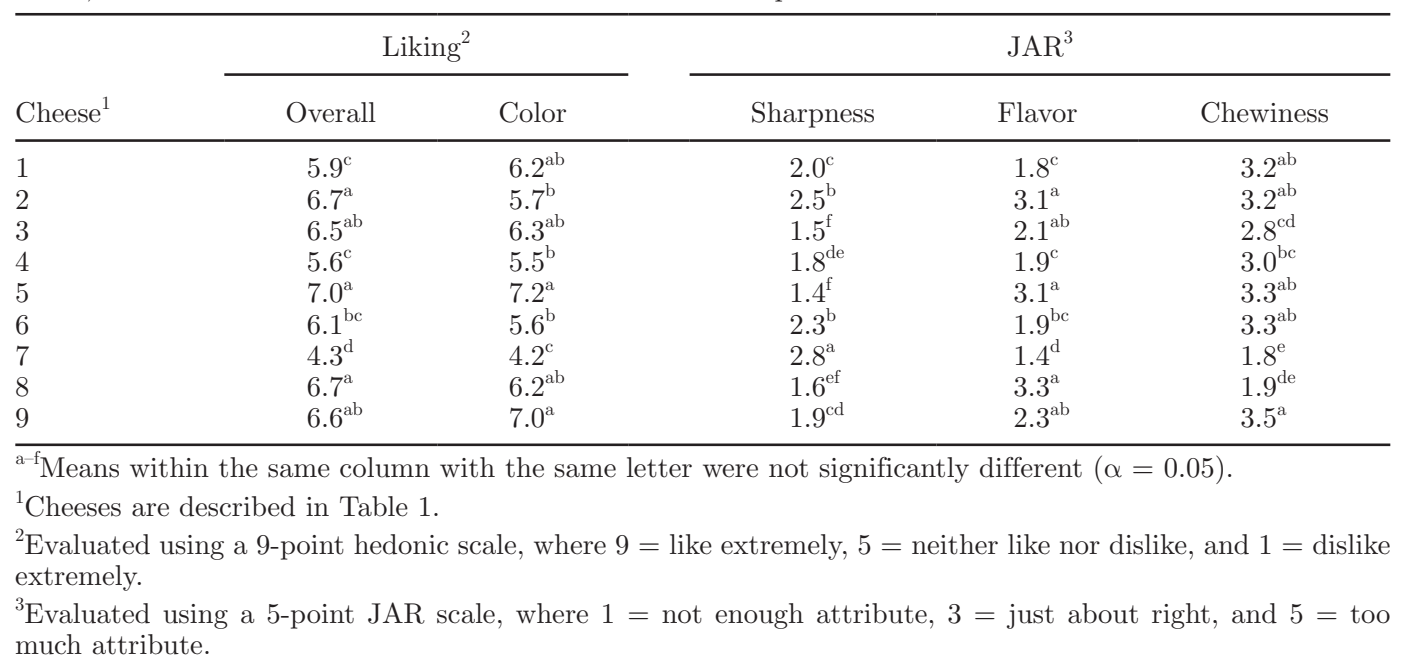

for both overall liking and color (7.0 and 7.2, respectively). Interestingly, this is a higher overall liking score than the 6.8 that was given to the full-fat cheese with the highest overall liking score (cheese A mild) and only slightly lower than the highest color-liking score (Table 5). Low-fat cheeses $2,3,8$, and 9 also had high overall liking scores, which were not significantly different from cheese 5. Similarly, cheeses 1, 3, 8, and 9 had high colorliking scores (Table 8).

Using the attributes diagnostic test, significant differences were found among the low-fat cheeses for sharpness $(P=0.044)$, flavor $(P=0.023)$, and chewiness $(P=0.003)$. When considering the low-fat cheeses using the JAR scale, cheeses made with the intermediate level of titanium dioxide (cheeses 2, 5, and 8) were the closest to being JAR for flavor, with scores of 3.1, 3.1 , and 3.3, respectively (Table 8). Cheeses 3 and 9 were scored as being slightly not enough flavor (2.1 and 2.3 , respectively), although these were not significant from cheeses 2,5 , and 8 at $\alpha=0.05$. The cheese with the lowest JAR flavor score of 1.4 was cheese 7 , which corresponds to having the lowest overall liking score. Interestingly, cheese 7 had a JAR sharpness score of 2.8 , whereas all of the other cheeses had lower scores. Most of the cheeses were considered JAR for chewiness ( scores $=2.8$ to 3.3 ), whereas cheese 7 and 8 were considered not chewy enough (scores $=1.8$ and 1.9, respectively). Cheese 9 had the most chewiness $(P<$ $0.05)$ with a JAR score of 3.5.

\section{DISCUSSION}

\section{Cheese Color}

Flavor and texture are well-known issues for low-fat cheeses (Drake and Swanson, 1995; Johnson et al., 2010) and consumers are unwilling to sacrifice the flavor or texture qualities of cheese for the sake of purchasing a cheese with reduced fat content (Childs and Drake, 2009). From our study, it is apparent that the color of lower-fat cheeses is also important and even affects the consumer perception of flavor. Low-fat cheeses that were translucent (cheeses 1, 4, and 7) were considered unappealing, with the lowest JAR flavor scores (even though their flavors were essentially identical).

This translucency comes about because of the lack of light scattering centers in cheese when fat is removed and when the cheese chemistry is adjusted so that the cheese does not become too rubbery (Pastorino et al., 2002). Consumers have probably come to expect such translucency in cheeses with very low fat content (from their observations of what is available in the retail market) and just like with fluid milk, the perception of fat level (from 0 to $4 \%$ ) is inversely related to transparency (Phillips et al., 1995). When high levels of annatto are used in making low-fat cheese so as to impart the typical yellow-orange color, the translucency of the cheese results in a dark orange color that makes the cheese appear very different from full-fat cheese. Such cheeses are not liked by consumers, as shown by cheese 7 receiving the lowest scores for JAR flavor as well as color and overall liking.

In this study, it was apparent that consumers prefer some opaqueness of cheese no matter if the cheese is uncolored or colored with annatto. Cheeses 2 (no annatto) and 5 and 8 (intermediate and high annatto levels) were those considered to be closest to JAR for flavor, with scores of 3.1,3.1, and 3.3, respectively. This opacity was achieved by addition of titanium dioxide during cheesemaking, and for many years, titanium dioxide was used only in non-food applications such as 
in solar cells, as white pigment in paints and coating, in ceramics, and in electric devices (Diebold, 2003). Its use in the US food industry has increased since it was approved in 1966 for food-contact applications and as a food coloring [21 Code of Federal Regulations (CFR) 73.575; Phillips and Barbano, 1997].

The 3 low-fat cheeses that did not have any added annatto (cheeses 1, 2, and 3) were slightly liked to moderately liked with scores of 5.9, 6.7, and 6.5, respectively. Even though cheese 1 had similar translucency as cheese 7 , it was apparently not considered undesirable, as shown by its color liking score of 6.2. Providing the desired opacity to the cheese (cheese 2) increased its overall liking $(P<0.05)$ and its flavor perception to being JAR (Table 8). As the extent of whiteness was further increased (cheese 3), the flavor perception tended to be lower and the cheese was considered as having slightly not enough flavor. We speculate this may be a result of cheese 2 and 3 looking like Feta and low-moisture, part-skim Mozzarella cheese, respectively, and their having mild and strong flavors, respectively. Some consumer panelists did comment that cheese 3 looked like Mozzarella cheese, and we observed that $\mathrm{L}^{*}, \mathrm{a}^{*}$, and $\mathrm{b}^{*}$ values for cheeses 2 and 3 were very similar to those of Feta and low-moisture, part-skim Mozzarella cheese (data not shown).

We had speculated that it may be the bitter attribute of cheese that was causing the difference in consumer perception of flavor and sharpness. However, no consistent trend between cheese bitterness and overall liking scores was apparent. Bitterness in cheese can be caused by accumulation of proline-containing peptides released from the caseins and degradation of these peptides requires the presence of proline-specific peptidases such as post-proline dipeptidyl aminopeptidases (Guinee and Kilcawley, 2004). It has recently been observed that titanium dioxide under UV light illumination can catalyze peptide cleavage adjacent to proline residues (Jones et al., 2007). The presence of titanium dioxide in low-fat cheese perhaps increases cleavage of such proline-containing peptides with consequently less accumulation of bitter peptides during storage of the cheese. This could explain the significantly lower bitterness in cheese $3($ score $=0.44)$ compared with cheese 1 and $2($ score $=1.50$ and 1.69, respectively; Table 7$)$. However, the same trend was not observed for cheeses containing both titanium dioxide and annatto.

\section{Cheese Flavor}

The low-fat cheeses were mild in flavor, as they had only been aged for $2 \mathrm{mo}$ at the time of sensory testing and, based on informal evaluation, lacked Ched- dar cheese flavor and had uncharacteristic brothy and burnt flavors. In comparison to the full-fat cheeses, whose flavor scores for umami and nutty increased with sharpness level (Table 5), the low-fat cheeses had scores that would place them in the mild-to-medium category. However, sharpness perception was different among the 9 cheeses. Cheese 7 was considered sharp, presumably because of its dark color, whereas cheeses 3, 5, and 8 were considered the mildest, presumably because of their whitish appearance. Clearly, consumer liking and perception of flavor of low-fat cheese is influenced by cheese color and so color of low-fat cheese should not be neglected when considering consumer preference and acceptance.

\section{CONCLUSIONS}

The overall liking of low-fat cheeses is highly dependent on its color and appearance. We observed that using different levels and combinations of annatto and titanium dioxide in low-fat cheeses directly affected consumer overall liking for these cheeses, and even influenced flavor and sharpness perception. Low-fat cheese colored with annatto (at levels similar to that used in full-fat Cheddar cheese) has an atypical translucent, dark orange color that is not well accepted by consumers and received the lowest overall liking score. Adding titanium dioxide increases cheese opacity so it looks more like full-fat cheese. If too much titanium dioxide is added, the low-fat cheese becomes too white in appearance and consumer liking decreases. In our study, low-fat cheese made with an intermediate level of both annatto and titanium dioxide scored the highest on overall liking with a score of 7.0 (on a 9-point hedonic scale), whereas cheese with the higher level of annatto and no titanium dioxide scored the lowest (overall liking $=4.3$ ), presumably because of its undesirably dark orange color and translucent appearance. This difference in appearance also influenced flavor perception. Although the 2 cheeses had the same flavor attributes (as evaluated by a trained sensory descriptive panel), the intermediate cheese was rated as JAR for flavor (JAR score $=3.1$ ), whereas the dark orange cheese was rated as having not enough flavor. (JAR score $=1.4$ ). Adding a low level of titanium dioxide to low-fat cheese made with either no annatto or high levels of annatto also resulted in high overall liking scores (6.7 for both) and JAR scores close to consumer expectations for flavor (3.1 and 3.3, respectively). This study demonstrates that for the manufacture of low-fat cheeses that will have good consumer acceptability, having the right level and combination of colorants is important. The low-fat cheeses made with optimum color were liked by 
the consumers as much as the full-fat mild and medium cheeses (mean overall liking scores of 6.5 to 7.0 compared with 6.1 to 6.8 , respectively).

\section{ACKNOWLEDGMENTS}

This research was conducted as part of the cheese applications program of the Western Dairy Center with funding provided by Dairy Management Inc., as administered by the Dairy Research Institute (Rosemont, IL). The authors thank David Irish, Curtis Maughan and Silvana Martini, and Xin Dai (all at Utah State University, Logan) for technical support in cheesemaking, sensory analysis, and statistical analysis, respectively. This research was supported by the Utah Agricultural Experiment Station, Utah State University and approved as paper no. 8378 .

\section{REFERENCES}

Carunchia Whetstine, M. E., M. A. Drake, J. R. Broadbent, and D. J. McMahon. 2006. Enhanced nutty flavor formation in Cheddar cheese made with a malty Lactococcus lactis adjunct culture. J. Dairy Sci. 89:3277-3284.

Childs, J. L., and M. A. Drake. 2009. Consumer perception of fat reduction in cheese. J. Sens. Stud. 24:902-921.

Clydesdale, F. M. 1993. Color as a factor in food choice. Crit. Rev. Food Sci. Nutr. 33:83-101.

CIE (Commission Internationale de l'Éclairage). 1978. Recommendations on Uniform Color Spaces, Color Difference Equations, Psychometric Color Terms. Supplement No. 2 to CIE Publication No. 15. Colorimetry, Bureau Central de la CIE, Paris, France.

Dave, R. I., D. J. McMahon, J. R. Broadbent, and C. J. Oberg. 2001. Reversibility of the temperature-dependent opacity of nonfat Mozzarella cheese. J. Dairy Sci. 84:2364-2371.

Delwiche, J. 2004. The impact of perceptual interactions on perceived flavor. Food Qual. Prefer. 15:137-146.

Diebold, U. 2003. The surface science of titanium dioxide. Surf. Sci. Rep. 48:53-229.

Drake, M. A. 2007. Invited review: Sensory analysis of dairy foods. J. Dairy Sci. 90:4925-4937.

Drake, M. A., S. C. McIngvale, P. D. Gerard, K. R. Cadwallader, and G. V. Civille. 2001. Development of a descriptive language for Cheddar cheese. J. Food Sci. 66:1422-1427.

Drake, M. A., and B. G. Swanson. 1995. Reduced- and low-fat cheese technology: A review. Trends Food Sci. Technol. 6:366-369.

Drake, M. A., M. D. Yates, and P. D. Gerard. 2008a. Determination of regional flavor differences in U. S. Cheddar cheeses aged for 6 mo or longer. J. Food Sci. 73:S199-S208.

Drake, S. L., P. D. Gerard, and M. A. Drake. 2008b. Consumer preferences for mild Cheddar cheese flavors. J. Food Sci. 73:S449-S455.

Drake, S. L., K. Lopetcharat, S. Clark, H. S. Kwak, S. Y. Lee, and M. A. Drake. 2009. Mapping differences in consumer perception of sharp Cheddar cheese in the United States. J. Food Sci. 74:S276S285.

FDA. 2011. Code of Federal Regulations Title 21, Part 73. Cheese and Related Cheese Products. Food and Drug Administration, Department of Health and Human Services, Washington, DC.

Francis, F. J. 1995. Quality as influenced by color. Food Qual. Prefer. 6:149-155

Guinee, T. P., and K. N. Kilcawley. 2004. Cheese as an ingredient Page 422 in Cheese: Chemistry, Physics and Microbiology, Vol. 2: Major Cheese Groups. 3rd ed. P. F. Fox., P. L. H. McSweeney,
T. M. Cogan, and T. P. Guinee. Elsevier Academic Press, San Diego, CA.

HunterLab. 2011. Measurement values. Chapter 9 in D25LT User's Manual, Version 1.4. Accessed Oct. 26, 2011. http://www.hunterlab.com/TrainingSupport/UserManuals/D25LTManual.

Hutchings, J. B. 2003. Expectations and the Food Industry: The Impact of Color and Appearance. Kluwer Academic/Plenum Publisher, New York, NY.

Johnson, M. E., R. Kapoor, D. J. McMahon, D. R. McCoy, and R. G. Narasimmon. 2010. Reduction of sodium and fat levels in natural and processed cheeses: Scientific and technological aspects. Comp. Rev. Food Sci. Food Safety 8:252-268.

Jones, B. J., M. J. Vergne, D. M. Bunk, L. E. Locascio, and M. A. Hayes. 2007. Cleavage of peptides and proteins using light-generated radicals from titanium dioxide. Anal. Chem. 79:1327-1332.

MacEvoy, B. 2009. Color wheels. Accessed Aug. 15, 2011. http://www. handprint.com/HP/WCL/color13.html\#top.

Marsili, R. 1985. Monitoring chemical changes in Cheddar cheese during aging by high performance liquid chromatography and gas chromatography techniques. J. Dairy Sci. 68:3155-3161.

Meilgaard, M. C., G. V. Civille, and B. T. Carr. 2007. Sensory Evaluation Techniques. 4th ed. CRC Press, Boca Raton, FL.

Merrill, R. K., C. J. Oberg, and D. J. McMahon. 1994. A method for manufacturing reduced fat Mozzarella cheese. J. Dairy Sci. 77:1783-1789.

Morrot, G., F. Brochet, and D. Dubourdieu. 2001. The color of odors Brain Lang. 79:309-320.

Pangborn, R. M., H. W. Berg, and B. Hansen. 1963. The influence of color on discrimination of sweetness in dry table wine. Am. J. Psychol. 76:492-495.

Pastorino, A. J., R. I. Dave, C. J. Oberg, and D. J. McMahon. 2002 Temperature effect on structure-opacity relationships of nonfat Mozzarella cheese. J. Dairy Sci. 85:2106-2113.

Paulson, B. M., D. J. McMahon, and C. J. Oberg. 1998. Influence of salt on appearance, functionality, and protein arrangements in nonfat Mozzarella cheese. J. Dairy Sci. 81:2053-2064.

Phillips, L. G., and D. M. Barbano. 1997. The Influence of fat substitutes based on protein and titanium dioxide on the sensory properties of low-fat milks. J. Dairy Sci. 80:2726-2731.

Phillips, L. G., M. Mcgiff, D. M. Barbano, and H. T. Lawless. 1995 The influence of fat on the sensory properties, viscosity, and color of low-fat milk. J. Dairy Sci. 78:1258-1266.

Richardson, G. H., ed. 1985. Page 351 in Standard Methods for the Examination of Dairy Products. 15th ed. Am. Publ. Health Assoc., Washington, DC

Roth, H. A., L. J. Radle, S. R. Gifford, and F. M. Clydesdale. 1988. Psychophysical relationships between perceived sweetness and color in lemon- and lime-flavored drinks. J. Food Sci. 53:1116-1119.

SAS Institute. 1999. SAS User's Guide: Statistics. Version 6.0. SAS Institute Inc., Cary, NC

Singh, S. 2006. Impact of color on marketing. Manage. Decis. 44:783789.

Sipahioglu, O., V. B. Alvarez, and C. Solano-Lopez. 1999. Structure, physico-chemical and sensory properties of Feta cheese made with tapioca starch and lecithin as fat mimetics. Int. Dairy J. 9:783789.

USDA. 2001. USDA Specifications for Shredded Cheddar Cheese. United States Department of Agriculture, Agricultural Marketing Service, Dairy Programs. Accessed Oct. 27, 2011. http://www. ams.usda.gov/AMSv1.0/getfile?dDocName=STELDEV3004548.

USDA. 2011. 7 CFR 1170.8 (a) (6) Dairy Product Mandatory Reporting. Department of Agriculture, Agricultural Marketing Service. Accessed Oct. 27, 2011. http://ecfr.gpoaccess.gov/cgi/t/text/textidx? $\mathrm{c}=\mathrm{ecfr} ; \mathrm{sid}=15 \mathrm{af} 34 \mathrm{~d} 381 \mathrm{e} 1 \mathrm{~d} 8 \mathrm{fb} 71 \mathrm{a} 4 \mathrm{ff} 35 \mathrm{f} 6 \mathrm{cb} 8249 ; \mathrm{rgn}=\operatorname{div} 5 ;$ view $=$ text $;$ node $=7 \% 3 \mathrm{~A} 9 \cdot 1 \cdot 1 \cdot 1 \cdot 24 ; \mathrm{idno}=7 ; \mathrm{cc}=\mathrm{ecfr} \# 7: 9.1 \cdot 1 \cdot 1 \cdot 24.0 .187 .8$

Yates, M. D., and M. A. Drake. 2007. Texture properties of Gouda cheese. J. Sens. Stud. 22:493-506.

Young, N. D., M. A. Drake, K. Lopetcharat, and M. R. McDaniel 2004. Preference mapping of Cheddar cheese with varying maturity levels. J. Dairy Sci. 87:11-19. 